\title{
BMJ Open NSAIDs, statins, low-dose aspirin and PPIs, and the risk of oesophageal adenocarcinoma among patients with Barrett's oesophagus: a population- based case-control study
}

\author{
Gwen M C Masclee, ${ }^{1,2}$ Preciosa M Coloma, ${ }^{1}$ Manon C W Spaander, ${ }^{2}$ \\ Ernst J Kuipers, ${ }^{2}$ Miriam C J M Sturkenboom ${ }^{1,3}$
}

To cite: Masclee GMC, Coloma PM, Spaander MCW, et al. NSAIDs, statins, low-dose aspirin and PPIs, and the risk of oesophageal adenocarcinoma among patients with Barrett's oesophagus: a populationbased case-control study. BMJ Open 2015;5:e006640. doi:10.1136/bmjopen-2014006640

- Prepublication history and additional material is available. To view please visit the journal (http://dx.doi.org/ 10.1136/bmjopen-2014006640).

Received 15 September 2014 Revised 9 November 2014 Accepted 7 January 2015

CrossMark

For numbered affiliations see end of article.

Correspondence to Gwen M C Masclee; g.masclee@erasmusmc.nl

\section{ABSTRACT}

Objectives: Non-steroidal anti-inflammatory drugs (NSAIDs), proton pump inhibitors (PPIs), low-dose aspirin and statins may decrease the risk of oesophageal adenocarcinoma (OAC) among patients with Barrett's oesophagus (B0). However, previous studies did not adequately address bias and confounding. Our objective was to estimate the risk of OAC among patients with BO exposed to NSAIDs, statins and PPIs.

Design: Case-control study nested within a BO cohort.

Setting: Two primary care databases (the UK and the Netherlands (NL)).

Participants: Cases were adults $\geq 18$ years of age with OAC or high-grade dysplasia (HGD) diagnosis $\geq 1$ year after $\mathrm{BO}$ diagnosis. Controls were matched on age, sex, year of BO diagnosis and database.

Exposure: Drug use was assessed from BO diagnosis until matching date.

Outcome measure: Adjusted ORs with $95 \% \mathrm{Cl}$ were calculated by conditional logistic regression.

Results: Within the BO cohort $(n=15134), 45$ OAC (UK: 40, NL: 5) and 12 HGD cases (NL: 12) were identified. ORa for OAC during NSAID use was 1.2 $(95 \% \mathrm{Cl} 0.6$ to 2.5$)$ and during statin use for $>3$ years 0.5 (95\% Cl 0.1 to 1.7). When including HGD cases $(\mathrm{n}=57)$, ORa for NSAID use was $0.9(95 \% \mathrm{Cl} 0.5$ to 1.8) and for statin use $>3$ years $0.5(95 \% \mathrm{Cl} 0.1$ to 1.7). Higher doses of statins showed lower estimates for OAC and HGD, though not statistically significant. Low-dose aspirin and PPIs did not significantly decrease the risk of OAC and HGD.

Conclusions: In this population-based nested casecontrol study, use of NSAIDs, PPIs, low-dose aspirin or statins did not reduce the risk of HGD and OAC among patients with $\mathrm{BO}$. These findings indicate that for an unselected group of patients with BO chemoprevention by use of drugs to reduce progression to HGD and OAC should not be directly considered as routine care.

\section{Strengths and limitations of this study}

- Within a population-based cohort of incident Barrett's oesophagus (BO) patients derived from two European countries, and applying a common study protocol and drug exposure definition, the risk of development of oesophageal adenocarcinoma (OAC) was estimated during use of several drugs individually and concomitantly.

- We were able to minimise certain biases, for instance, due to availability of drug prescription data recall bias was avoided and by using a population-based approach selection bias was minimised.

- The small number of OAC cases that was identified limited the power for the duration analyses.

- We did not have detailed pathology information on the Barrett segment length or grade of dysplasia at cohort entry for every BO cohort member in both countries. This may have resulted from including patients with a short segment BO who may be at lower risk of developing high-grade dysplasia and $\mathrm{OAC}$ at the outset.

\section{INTRODUCTION}

Barrett's oesophagus (BO) is a premalignant condition in which the squamous epithelium of the oesophagus is replaced by metaplastic columnar epithelium. ${ }^{1} \mathrm{BO}$ is considered a consequence of prolonged gastro-oesophageal reflux $^{2}$ and is the most important risk factor for development of oesophageal adenocarcinoma (OAC) via a stepwise pathway of low-grade and high-grade dysplasia (HGD). It is estimated that the risk of OAC is increased by approximately 30-125-fold in persons with $\mathrm{BO},{ }^{3}$ and occurs in a small proportion of patients with $\mathrm{BO}$ yearly. ${ }^{4}$ Endoscopic surveillance for $\mathrm{BO}$ is therefore recommended. ${ }^{2}$

In recent decades, the incidence of $\mathrm{BO}$ increased, accompanied by a marked increase 
in OAC incidence in the USA and Western Europe. ${ }^{5} 6$ However, estimates of OAC incidence among patients with BO vary substantially. ${ }^{7-10}$ Generally, gastrointestinal cancers account for $25 \%$ of all cancers and approximately $4.9 \%$ of all deaths worldwide. ${ }^{11}$ Death rates of most cancers decreased in recent years in contrast to the $3 \%$ increase in death rates of all oesophageal cancers (squamous cell carcinoma as well as adenocarcinoma) among males. ${ }^{11}$ The age-standardised mortality rate for oesophageal cancer overall is 5.1/100 000 persons. ${ }^{6}$ The need for effective prevention of oesophageal cancer, in general, is therefore warranted, particularly given the low 5-year survival rate of $13-17 \% .^{12}$

Several studies reported that use of non-steroidal antiinflammatory drugs (NSAIDs), low-dose aspirin, statins and proton pump inhibitors (PPIs) may decrease the risk of OAC among patients with $\mathrm{BO} \cdot{ }^{13-21}$ However, these studies were based on small, selected samples of OAC cases. PPIs are considered standard care for symptom relief in patients with $\mathrm{BO}$, thus it was suggested that PPIs may decrease the risk of progression to HGD or OAC. ${ }^{20} \mathrm{In}$ contrast, other studies showed an increase in risk of OAC with PPI use, probably because the underlying treatment indication may be a risk factor for $\mathrm{OAC}$ rather than that PPIs being harmful for OAC among patients with BO. ${ }^{15} 22$ Nevertheless, one cannot directly assume that PPIs, which are efficacious for treatment of erosive oesophagitis, will also be beneficial in the pathway from $\mathrm{BO}$ to OAC development. Two meta-analyses both including nine observational studies showed that the risk of oesophageal cancer ${ }^{14}$ and $\mathrm{HGD} / \mathrm{OAC}^{23}$ among those who frequently use NSAIDs or aspirin was significantly lower compared with never users. ${ }^{14}$ However, studies included in the earlier meta-analysis did not specifically include patients with BO. A pooled analysis on individual patient data confirmed the significant reduction in risk of OAC in patients with $\mathrm{BO}$ with NSAID prescriptions. ${ }^{24}$ Two case-control studies observed an association between use of NSAIDs ${ }^{15}$ and statins, ${ }^{15} 25$ and the risk of OAC among patients with BO. Generalisation and extrapolation of results from the latter studies to the general population is, however, difficult as both studies were performed in US veterans. ${ }^{15} 25$ Additionally, there was no adjustment for important risk factors of OAC progression such as alcohol use and smoking. ${ }^{15}$ Nevertheless, a recent systematic review and meta-analysis showed a risk reduction in development of oesophageal cancer in general and OAC among patients with $\mathrm{BO}$ who took statins. ${ }^{26}$

Causality of an apparent association is generally supported by a dose-duration relationship. ${ }^{27}$ However, studies to date neither reported a clear exposure definition free of recall bias ${ }^{13} 1624$ nor conducted dose-duration analyses. Finally, concerns have been raised about publication bias of these studies on chemoprevention of OAC in patients with BO. ${ }^{18}$

Thus, to what extent NSAIDs, low-dose aspirin, statins and PPIs may reduce the risk of OAC among patients with $\mathrm{BO}$ in clinical practice remains unknown.
Therefore, we conducted a matched case-control study to evaluate the risk of OAC among patients with $\mathrm{BO}$ associated with use of NSAIDs, low-dose aspirin, statins and PPIs.

\section{MATERIALS AND METHODS \\ DATA sources}

Two European population-based general practice registries served as data sources: (1) The Health Improvement Network (THIN) from the UK (1996-2011) ${ }^{28}$ and (2) the Integrated Primary Care Information database (IPCI) from the Netherlands (NL, 1996-2012).$^{29}$ Both databases contain prospectively collected data that represent real-life practice. In the UK and in NL, all citizens are registered with a general practitioner (GP), who acts as a gatekeeper to secondary and tertiary medical care. THIN collects anonymised data on more than 3 million active patients from over 400 participating general practices, IPCI contains over 1.5 million active patients from 340 practices. For each individual patient all relevant medical information, from primary and secondary care, as well as additional information, including demographics and drug prescriptions, is documented in the medical record. Both data sources comply with European Union guidelines on the use of medical data for research.

THIN employs the READ clinical terminology system for coding medical diagnosis and symptoms,${ }^{30}$ whereas IPCI uses the International Classification for Primary Care (ICPC).${ }^{31}$ Information on drug prescriptions is captured in THIN with the Multilex product dictionary and British National Formulary (BNF) codes, whereas in IPCI, information on drug prescriptions is coded according to the WHO's Anatomical Therapeutic Chemical (ATC) classification. ${ }^{32}$ Identification of the source and study population has been described previously. ${ }^{10}$

\section{Source population}

The source population consisted of all patients aged $\geq 18$ years who contributed data to the database between 1 January 1996 and 31 December 2011 (THIN) or March 2013 (IPCI). At least 1 year of available data prior to study entry were required to assess patient's medical history for exclusion criteria and risk factors. Follow-up started on 1 January 1996, or the date of reaching 18 years of age, or the date that 1 year of valid data were accrued within the database, whichever came later Follow-up ended on the date of occurrence of study outcome (OAC), date of transfer out of the GP's practice, death, or last data drawn, whichever was earliest.

\section{Definition of $\mathrm{BO}$}

Patients with BO were identified using diagnosis codes; in THIN using corresponding READ codes (online supplementary appendix table 1$).{ }^{30}$ In IPCI, each potential BO case was manually validated to confirm the histological diagnosis of $\mathrm{BO}$ and the date of first diagnosis or mentioning of $\mathrm{BO}$ in the clinical record. Patients were 
excluded if they had a history of oesophageal cancer anytime before $\mathrm{BO}$ diagnosis and if they had a history of gastric cancer within 6 months after $\mathrm{BO}$ diagnosis. In IPCI, we could utilise free text from the medical record to assess the Barrett segment length and grade of dysplasia.

\section{Definition of OAC}

In THIN, OAC cases were identified by READ codes (online supplementary appendix table 1). In IPCI, all patients with a record of ICPC codes D77.1 (malignant neoplasia of the oesophagus) and D77.0 (malignant neoplasia of the digestive tract-not specified), or with a record from free text search including word combinations of 'oesophagus', 'cancer', 'carcinoma', 'malignancy' or 'neoplasia', were identified. Similar to BO, all potential cases were manually validated for confirmation of the OAC diagnosis, date of first diagnosis and the type of carcinoma (squamous cell carcinoma, adenocarcinoma, or other types of carcinoma). Early cancer (HGD) was identified in IPCI also, but could not be assessed in THIN.

We only considered incident HGD or OAC cases: that is, if the date of diagnosis occurred after inclusion into the $\mathrm{BO}$ cohort and was at least 12 months after $\mathrm{BO}$ diagnosis. Cases occurring within 1 year from $\mathrm{BO}$ diagnosis were considered to be already existent at $\mathrm{BO}$ diagnosis date and in relation to the $\mathrm{BO}$ diagnostic work-up.

\section{Cases and controls selection}

Two nested case-control studies were conducted assessing the risk of OAC for use of four drugs (NSAIDs, PPIs, statins and low-dose aspirin); one including only OAC cases and a second case-control study including HGD cases from IPCI as well.

Cases were adults diagnosed with $\mathrm{OAC} \geq 12$ months after BO diagnosis, because cases occurring within 1 year of $\mathrm{BO}$ diagnosis were considered to be existent and related to $\mathrm{BO}$ diagnostic work-up (eg, missed OAC at $\mathrm{BO}$ diagnosis). Index date was defined as date of first reporting of OAC diagnosis during follow-up. Controls were members of the incident $\mathrm{BO}$ cohort who did not develop OAC up to matching date. Controls were matched by incidence density sampling on age ( \pm 5 years), sex, year of BO diagnosis ( \pm 1 year) and database. We matched on year of BO diagnosis in order to account for any influence of guideline changes in endoscopic surveillance over calendar time.

\section{Drug exposure}

Drug exposures of interest included four drug groups: NSAIDs, PPIs, statins and low-dose aspirin. They were assessed in terms of outpatient prescriptions for NSAIDs (including high-dose aspirin, ie, $>325 \mathrm{mg} /$ day), PPIs, statins and low-dose aspirin (up to $325 \mathrm{mg} /$ day) from $\mathrm{BO}$ diagnosis until OAC diagnosis. In order to compare the OR of NSAIDs, PPIs and statins to other drugs, we considered another group of medications, which served as control. Antidepressants (selective serotonin re-uptake inhibitors (SSRIs)) are currently not known to be either positively or negatively associated with OAC.

Duration of prescriptions was calculated based on the prescribed quantity and dosing regimen. As the most likely preventive effect of drugs on cancer progression is through a cumulative mechanism, we calculated all duration and defined daily dose (DDD) values from date of BO diagnosis until index date. Duration was classified according to never use (reference category), cumulative use of less than 1 month, between 1 and 12 months, $>12$ months (or if applicable 1-2 years; 2-3 years and $>3$ years). Considering that PPIs are indicated as treatment for patients with $\mathrm{BO}$, duration was classified as 0-6 months (reference category), 6-12 months, 1-2 years and $>2$ years. Dose of exposure was classified using the ratio of prescribed daily dose compared with DDD using quartiles into categories $(<0.8,0.8-1.2, \geq 1.2$ DDD per day). As there is no DDD for low-dose aspirin, dose analysis was not performed for use of low-dose aspirin.

\section{Potential confounders}

We considered as potential confounders: concurrent diagnosis of oesophagitis or gastritis within 1 year before BO diagnosis; hiatal hernia; smoking habits (nonsmoker, ex-smoker, current smoker) and alcohol abuse (never, current, past).

\section{Statistical analyses}

Baseline characteristics of cases and controls were described per database and compared using univariate conditional logistic regression.

To estimate the risk of HGD and OAC among patients with BO, matched and adjusted ORs (ORa) with 95\% CIs were calculated using conditional logistic regression for both databases separately and as a pooled analysis on patient-level pooled data.

Potential confounders were included in the adjusted analysis (ORa) if they resulted in a change of more than $10 \%$ of the initial estimate. Time since $\mathrm{BO}$ diagnosis was forced into the adjusted model.

Subsequent analyses included dose-duration analyses. The risk of OAC and HGD-OAC was also assessed for concomitant use of NSAIDs, low-dose aspirin, statins and/or PPIs. Use of PPIs only was considered as reference category considering that PPIs are standard therapy for BO.

All analyses were performed using SAS V.9.2 (Cary, North Carolina, USA).

\section{Power calculation}

Given an exposure prevalence of NSAIDs of $30 \%$, statins of $22 \%$ or $36 \%$, PPIs of $87 \%$ or $52 \%$ and low-dose aspirin of $25 \%$ among controls and a correlation of 0.5 between exposed and unexposed patients we have $80 \%$ power (with a type 1 error of $5 \%$ ) to detect a true OR of OAC of 0.34 for NSAIDs, around $0.38-0.40$ for statins, around $0.32-0.45$ for PPIs and 0.29 for low-dose aspirin, which would be in concordance with previous studies. 


\section{RESULTS}

\section{Study population}

From the source population of 7570765 patients in the UK and 1496276 patients in NL we identified 13696 and 1438 incident BO cases, respectively. Men accounted for $63 \%$ (the UK) and $62 \%$ (NL) of patients with BO. Mean age at BO diagnosis was 64.8 (SD 13.8) years in the UK and 61.2 (SD 13.4) years in NL.

In the UK, we identified 40 incident $\mathrm{OAC}$ cases within the BO cohort $(0.3 \%)$ to whom we could match 656 controls. Median number of controls per case was 17 (IQR 9-23). In NL we identified five incident OAC cases among the BO cohort $(0.3 \%)$. These were matched to 76 control subjects, with a median of 5 controls per case (IQR 4-6). In addition, we identified 12 HGD cases, resulting in a second case-control set of 17 cases (5 OAC+12 HGD) matched to 753 controls (median 44 controls; IQR 6-61). Figure 1 shows a flowchart of the study population. Table 1 provides baseline characteristics of cases and controls. In the UK, a larger proportion of cases had a body mass index (BMI) over $25 \mathrm{~kg} / \mathrm{m}^{2} ; 68 \%$ of cases and $59 \%$ of controls. In NL, the BMI of only one case within 1 year of OAC diagnosis was available $\left(21.3 \mathrm{~kg} / \mathrm{m}^{2}\right)$. Controls had a mean BMI of $28.7 \mathrm{~kg} / \mathrm{m}^{2}$ (SD 4.7) in NL. Presence of oesophagitis or gastritis at time of $\mathrm{BO}$ diagnosis was more often seen in controls than in cases. In the UK, a hiatal hernia was more often present among cases, whereas the opposite was found in NL. In the UK, OAC cases were more likely to be current smokers than controls (OR 3.3; $95 \%$ CI 1.4 to 8.0 ), as seen in NL, though not significantly. Mean time from BO diagnosis until OAC diagnosis was 4.2 (SD 2.5) years in the UK and 3.5 (SD 0.8) years in NL.

\section{Drug exposure}

Table 2 provides characteristics of drug use from BO diagnosis until index date for cases and controls per database. Statins were used by $30 \%$ and $0 \%$ of OAC cases; and by $36 \%$ and $22 \%$ of controls in the UK and NL, respectively. PPIs were used by OAC cases for a mean of 4.1 years (the UK) and 2.3 years (NL), and by controls for 2.9 years (the UK) and 1.9 years (NL). SSRIs were used by $12.5 \%$ of OAC cases in the UK for a mean duration of 1 year, and by $7.6 \%$ of controls for a mean duration of 1.7 years. Low-dose aspirin was used by $26 \%$ of patients with $\mathrm{BO}$ in the UK and $6 \%$ of patients with $\mathrm{BO}$ in NL.

\section{Risk of oesophageal adenocarcinoma}

To estimate the risk of OAC with use of NSAIDs, PPIs, statins and low-dose aspirin, a nested case-control study was conducted. From the adjusted model, on patientlevel pooled data, exposure to NSAIDs and PPIs did not provide a significant decrease in the risk of OAC (table 3); for statins a non-significant effect was seen (ORa $0.7 ; 95 \%$ CI 0.4 to 1.5 ). This was seen in both databases separately as well (data not shown).

For NSAID use, ORs ranged between 1.1 and 1.4 for all duration categories; regarding dose-analysis, no difference in risk was found between higher and lower dosages (table 4). Although not significant, a dose-duration-response was seen for statins, with lower OR for longer duration of use compared with non-use of statins. Statin use $\geq 1.2$ times higher compared to the recommended DDD resulted in an OR of 0.7 (95\% CI 0.2 to 2.3). For PPIs an increase in OR was seen with prolonged duration, in the matched and in the adjusted analyses. PPIs used at highest dose showed an OR for HGD-OAC of 0.9 (95\% CI 0.3 to 2.3). The ORs varied for duration categories of SSRIs. No dose-response was seen for SSRI use. Use of low-dose aspirin provided ORs below 1 for OAC for matched and adjusted analysis, when considering the exposure at any time between BO diagnosis and OAC diagnosis; however, the 95\% confidence limits still included the 1 . When considering
Figure 1 Flowchart of Barrett's oesophagus and oesophageal adenocarcinoma cases in the UK and the Netherlands. BO, Barrett's oesophagus; OAC, oesophageal adenocarcinoma; HGD, high-grade dysplasia; THIN, The Health Improvement Network; IPCI, Integrated Primary Care Information; PYs, person years.

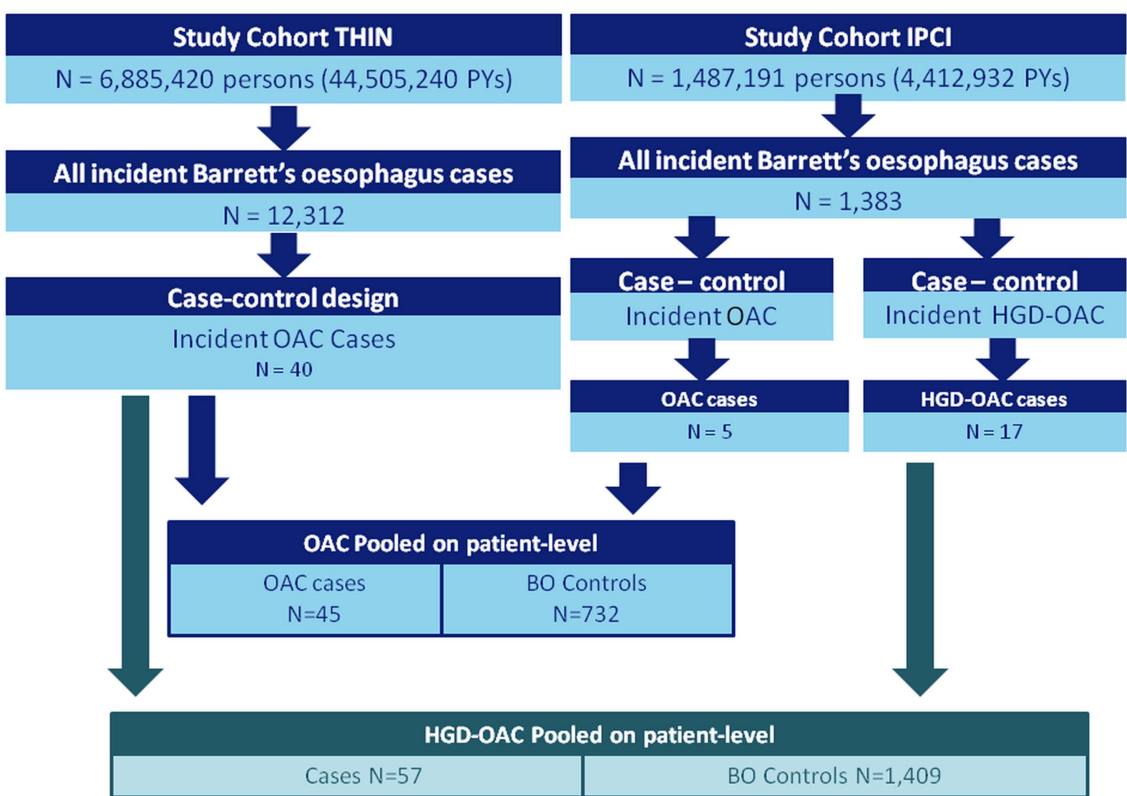


Table 1 Baseline characteristics of OAC cases and HGD cases in the UK and the Netherlands

\begin{tabular}{|c|c|c|c|c|c|c|c|c|}
\hline & \multicolumn{4}{|l|}{ The UK } & \multicolumn{4}{|c|}{ The Netherlands HGD-OAC } \\
\hline & $\begin{array}{l}\text { OAC case } \\
N(\%)\end{array}$ & Control N (\%) & OR (95\% Cl) & p Value & $\begin{array}{l}\text { HGD-OAC } \\
\text { Case N (\%) }\end{array}$ & $\begin{array}{l}\text { HGD-OAC } \\
\text { control N (\%) }\end{array}$ & OR (95\% Cl) & p Value \\
\hline Total & $40(100)$ & $656(100)$ & & & $17(100)$ & $753(100)$ & & \\
\hline OAC & & & & & $5(29.4)$ & & & \\
\hline HGD & & & & & $12(70.6)$ & & & \\
\hline \multicolumn{9}{|l|}{ Sex } \\
\hline Male & $33(82.5)$ & $597(91)$ & & & $11(65)$ & $524(70)$ & & \\
\hline Female & $7(17.5)$ & $59(9)$ & & & $6(35)$ & $229(30)$ & & \\
\hline Mean age at index date (SD) & $71.2(10.4)$ & $70.2(9.0)$ & & & $68.8(8.2)$ & $66.4(8.8)$ & & \\
\hline \multicolumn{9}{|l|}{ Age group (years) } \\
\hline$<50$ & $1(2.5)$ & $14(2.1)$ & & & $0(0)$ & $17(2.3)$ & & \\
\hline $51-65$ & $8(20)$ & $149(23)$ & & & $6(35)$ & $338(45)$ & & \\
\hline $66-80$ & $25(62.5)$ & $434(66)$ & & & $10(59)$ & $364(48)$ & & \\
\hline$>80$ & $6(15)$ & $59(9)$ & & & $1(5.9)$ & $34(4.5)$ & & \\
\hline BMI $\left(\mathrm{kg} / \mathrm{m}^{2}\right)$ mean $(\mathrm{SD})$ & $27.7(4.1)$ & $26.9(4)$ & $1.1(1.0$ to 1.1$)$ & 0.210 & $28.9(6.8)$ & $26.4(7.4)$ & 1.1 (0.9 to 1.3$)$ & 0.500 \\
\hline \multicolumn{9}{|l|}{ BMI categories } \\
\hline $18-25$ & $10(25)$ & $202(31)$ & & & $1(5.9)$ & $85(11)$ & & \\
\hline$<18$ & $0(0)$ & $7(1.1)$ & - & 0.989 & $0(0)$ & $22(2.9)$ & - & 0.997 \\
\hline$>25-30$ & $19(47.5)$ & $269(41)$ & 1.5 (0.7 to 3.3$)$ & 0.329 & $2(12)$ & $156(21)$ & $1.3(0.1$ to 14.7$)$ & 0.995 \\
\hline$>30-35$ & $7(17.5)$ & $89(14)$ & $1.8(0.7$ to 5.0$)$ & 0.246 & $0(0)$ & $73(9.7)$ & - & 0.995 \\
\hline$>35$ & $1(2.5)$ & $31(4.7)$ & $0.8(0.1$ to 7.0$)$ & 0.866 & $1(5.9)$ & $14(1.9)$ & $6.1(0.3$ to 112.1$)$ & 0.993 \\
\hline Missing & $3(7.5)$ & $58(8.8)$ & $1.0(0.3$ to 3.8$)$ & 0.992 & $13(76)$ & $403(54)$ & $2.0(0.3$ to 16.5$)$ & 0.994 \\
\hline \multicolumn{9}{|l|}{ Oesophagitis at BO diagnosis } \\
\hline No & $39(97.5)$ & 629 (95.9) & & & $14(82)$ & $525(70)$ & & \\
\hline Yes & $1(2.5)$ & $27(4.1)$ & $0.6(0.1$ to 4.7$)$ & 0.633 & $3(18)$ & $228(30)$ & $0.5(0.1$ to 1.8$)$ & 0.299 \\
\hline \multicolumn{9}{|l|}{ Gastritis at $\mathrm{BO}$ diagnosis } \\
\hline No & $38(95)$ & $621(94.7)$ & & & $13(76)$ & $582(77)$ & & \\
\hline Yes & $2(5)$ & $35(5.3)$ & $1.2(0.3$ to 5.2$)$ & 0.808 & $4(24)$ & $171(23)$ & 1.5 (0.5 to 4.9$)$ & 0.516 \\
\hline \multicolumn{9}{|l|}{ Hiatal Hernia at BO diagnosis } \\
\hline No & $33(82.5)$ & 579 (88.3) & & & $8(47)$ & $268(36)$ & & \\
\hline Yes & $7(17.5)$ & 77 (11.7) & $1.7(0.7$ to 4.0$)$ & 0.259 & $9(53)$ & $485(64)$ & 0.7 (0.2 to 2.0$)$ & 0.487 \\
\hline \multicolumn{9}{|l|}{ Excessive alcohol use } \\
\hline Never & $17(42.5)$ & $370(56)$ & Ref & & $17(100)$ & $713(94.7)$ & - & 0.991 \\
\hline Current & $22(55)$ & $276(42)$ & $2.0(1.0$ to 3.0$)$ & 0.048 & (0) & $40(5.3)$ & & \\
\hline Past & $1(2.5)$ & $10(1.5)$ & 2.8 (0.3 to 23.4$)$ & 0.345 & & & & \\
\hline \multicolumn{9}{|l|}{ Smoking } \\
\hline Never & $14(35)$ & 322 (49) & Ref & & $9(53)$ & $380(50.5)$ & Ref & \\
\hline Current & $9(22.5)$ & $70(11)$ & $3.3(1.4$ to 8.0$)$ & 0.009 & $8(47)$ & $373(49.5)$ & $1.5(0.5$ to 4.5$)$ & 0.443 \\
\hline Past & $17(42.5)$ & 264 (40) & 1.7 (0.8 to 3.7$)$ & 0.155 & & & & \\
\hline \multicolumn{9}{|l|}{ Index year } \\
\hline 1998 & $1(2.5)$ & $7(1.1)$ & & & $1(5.9)$ & $5(0.7)$ & & \\
\hline 2000 & $1(2.5)$ & $12(1.8)$ & & & $1(5.9)$ & $4(0.5)$ & & \\
\hline
\end{tabular}




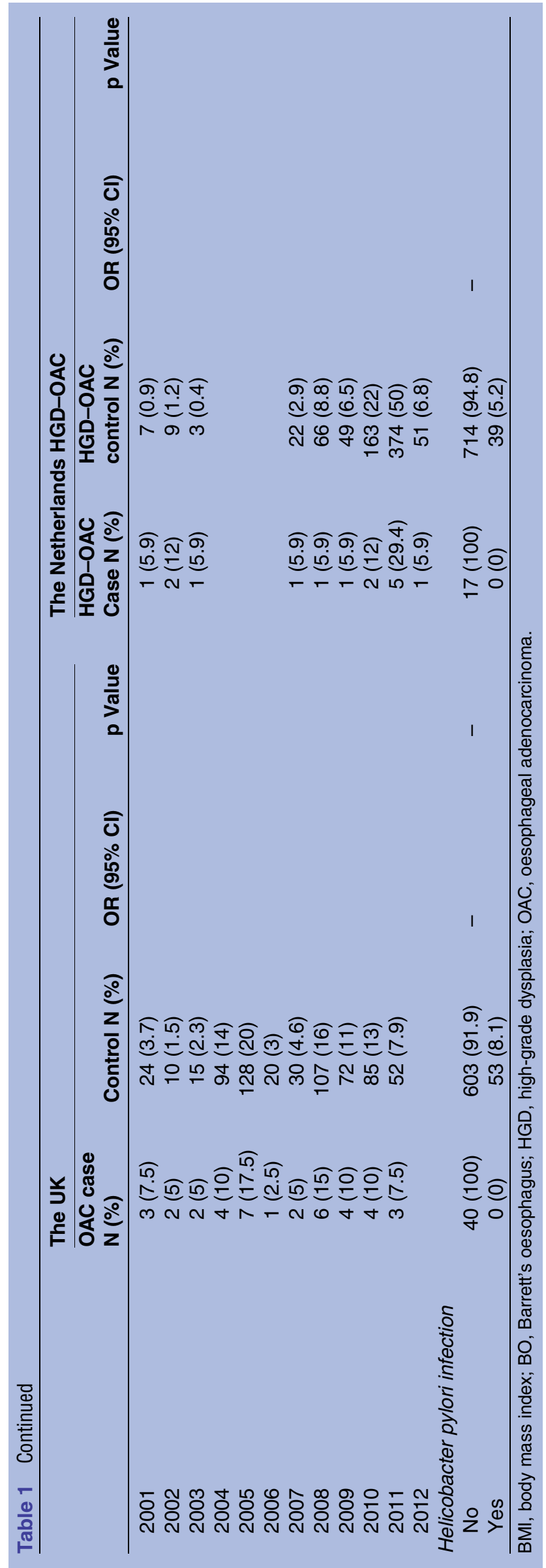

duration analysis, the adjusted model provided for the prolonged duration of use ( $>1$ year) an OR of $0.9(95 \%$ CI 0.4 to 2.1 ).

Concomitant use of drugs of interest did not decrease the risk of OAC (table 5) compared with use of PPIs only, probably due to the smaller number of cases.

\section{Risk of high-grade dysplasia or oesophageal adenocarcinoma}

In NL, we were able to retrieve HGD cases as well. When including these in the case definition, the effects were attenuated but in the same direction as the case-control study including OAC cases only. There was no significant decrease in the risk of HGD-OAC for exposure to NSAIDs, statins, PPIs and low-dose aspirin in the adjusted analysis (table 3). For NSAIDs, the OR increased with use of higher dosages (table 4). Again, for statins, a durationresponse relationship with the longest duration yielding the lowest ORa $(0.5 ; 95 \%$ CI 0.1 to 1.7$)$ and an inverse association with increasing dose was observed, though none significant. For low-dose aspirin, PPI and SSRI use, no dose-response effects were shown.

The risk of HGD-OAC was $13 \%$ lower for concomitant use of NSAIDs+PPIs (ORa $0.9 ; 95 \%$ CI 0.3 to 2.2; table 5). None of the associations were statistically significant.

\section{DISCUSSION}

In this population-based case-control study nested within a cohort of patients with $\mathrm{BO}$, statin use may decrease the risk of OAC and HGD by up to $50 \%$. PPIs did not reduce the risk of HGD and OAC, however, only when used at highest dose (eg, at least 1.2 times the recommended daily dose) a non-significant reduction may be present. In this unselected group of patients with BO, use of low-dose aspirin or NSAIDs was not associated with a decrease in risk of OAC. This is the first population-based study that looked at the preventive effect of these four different drugs used individually and also concomitantly.

The mechanism of OAC prevention is possibly related to inhibition of cyclo-oxygenase (COX)-2 production. Elevated levels of COX-2 in oesophageal epithelial cells have been observed in $\mathrm{BO}$, and noted to increase with disease progression from $\mathrm{BO}$ to $\mathrm{OAC} .{ }^{33}$ In experimental studies, COX-2 inhibitors inhibited the growth of $\mathrm{BO}$ cells, potentially through suppression of basic fibroblast growth factor. ${ }^{34}$ Another study confirmed that the end product of COX-2 conversion (prostaglandin E2) is reduced in patients with $\mathrm{BO}$ without HGD when using esomeprazole combined with higher doses (up to $325 \mathrm{mg}$ /day) of cardiovascular aspirin. ${ }^{35}$

Statins exert antineoplastic properties in several ways. By inhibition of the 3-hydroxy-3-methylglutanyl coenzyme A reductase enzyme, subsequent modulation of growth signal transduction, cellular proliferation and cell death is achieved, which affects different organs. ${ }^{36}$ In OAC cells particularly, statins inhibit cell proliferation and induce 
Table 2 Exposure characteristics of cases and controls in the UK and the Netherlands

\begin{tabular}{|c|c|c|c|c|}
\hline & \multicolumn{2}{|l|}{ The UK } & \multicolumn{2}{|l|}{ The Netherlands } \\
\hline & OAC case & Control & HGD-OAC case & $\begin{array}{l}\text { HGD-OAC } \\
\text { control }\end{array}$ \\
\hline & $\mathrm{N}=40$ & $\mathrm{~N}=656$ & $\mathrm{~N}=17$ & $N=753$ \\
\hline \multicolumn{5}{|l|}{ NSAIDs } \\
\hline Exposed-N & 11 & 148 & 2 & 102 \\
\hline Mean duration of use in days (SD) & 205 (373) & $218(348)$ & $18(4)$ & 49 (111) \\
\hline Mean cumulative DDD (SD) & $223(393)$ & $232(383)$ & $9(2)$ & $31(79)$ \\
\hline Median duration of use in days (IQR) & $40(20-178)$ & $56(28-203)$ & $18(15-20)$ & $15(10-60)$ \\
\hline Median cumulative DDD (IQR) & $40(30-223)$ & $56(28-208)$ & $9(7-10)$ & $10(5-30)$ \\
\hline \multicolumn{5}{|l|}{ Statins } \\
\hline Exposed-N & 12 & 236 & 3 & 123 \\
\hline Mean duration of use in days (SD) & $648(569)$ & $996(913)$ & $570(289)$ & $409(300)$ \\
\hline Mean cumulative DDD (SD) & 466 (353) & $1000(1258)$ & $560(191)$ & $383(331)$ \\
\hline Median duration of use in days (IQR) & $616(109-966)$ & $728(350-1386)$ & $450(360-900)$ & $330(180-629)$ \\
\hline Median cumulative DDD (IQR) & $504(110-775)$ & $625(243-1248)$ & $450(450-780)$ & $270(158-480)$ \\
\hline \multicolumn{5}{|l|}{ PPIs } \\
\hline Exposed-N & 36 & 570 & 10 & 389 \\
\hline Mean duration of use in days (SD) & $1500(1134)$ & $1071(978)$ & $615(462)$ & $442(372)$ \\
\hline Mean cumulative DDD (SD) & $1425(1247)$ & $1060(1123)$ & $576(402)$ & $661(1636)$ \\
\hline Median duration of use in days (IQR) & $1481(644-2017)$ & $766(392-1458)$ & $471(240-1020)$ & $315(180-630)$ \\
\hline Median cumulative DDD (IQR) & $1223(644-1772)$ & $700(364-1428)$ & $471(300-719)$ & $360(180-840)$ \\
\hline \multicolumn{5}{|l|}{ SSRIS } \\
\hline Exposed-N & 5 & 50 & 0 & 15 \\
\hline Mean duration of use in days (SD) & $369(280)$ & $613(705)$ & - & $743(669)$ \\
\hline Mean cumulative DDD (SD) & $366(283)$ & $843(1430)$ & - & $737(670)$ \\
\hline Median duration of use in days (IQR) & $252(252-504)$ & $381(90-840)$ & - & $600(180-1740)$ \\
\hline Median cumulative DDD (IQR) & $252(252-504)$ & $339(90-896)$ & - & $596(180-1740)$ \\
\hline \multicolumn{5}{|l|}{ Low-dose aspirin } \\
\hline Exposed-N & 10 & 173 & 1 & 47 \\
\hline Mean duration of use in days (SD) & $796(606)$ & $804(733)$ & 360 & $391(301)$ \\
\hline Mean cumulative DDD (SD)* & - & - & & - \\
\hline Median duration of use in days (IQR) & $672(448-1344)$ & $600(280-1096)$ & & $270(180-540)$ \\
\hline Median cumulative DDD (IQR) & - & - & & \\
\hline
\end{tabular}

*Low-dose aspirin ( $\leq 325 \mathrm{mg} /$ day) has no DDD value.

DDD, defined daily dose; HGD, high-grade dysplasia; NSAIDs, non-steroidal anti-inflammatory drugs; OAC, oesophageal adenocarcinoma; PPIs, proton pump inhibitors; SSRIs, selective serotonin re-uptake inhibitors.

apoptosis $^{37}$ and limit the metastatic potential by reducing intracellular adhesion molecules. ${ }^{38}$ However, statins also inhibit COX-2 expression in BO cells. ${ }^{39}$

Contrasting to other studies, we did not observe a significant preventive effect of NSAIDs, low-dose aspirin and statins with respect to the risk of HGDOAC. ${ }^{13-14} 24$ 40 Based on the biological mechanisms, combined use of statins and NSAIDs or statins with low-dose aspirin may be expected to result in a greater risk reduction compared to either drug alone. We did not observe NSAIDs or low-dose aspirin with statins combined resulting in a significant risk reduction of OAC. This may be due to several reasons. First, despite our large BO cohort, the number of identified cases was smaller. Although we may have not have identified all potential OAC cases from the database, in a casecontrol study this is not necessary to obtain unbiased estimates. However, it limited the power of the study and resulted in statistically non-significant results. For assessment of concomitant drug exposure, in particular, we did not reach statistical significance due to the lack of power, though this was not the primary aim of the study.

Our nesting cohort included all incident BO patients from the general population, and by matching on duration since BO diagnosis and excluding patients with prevalent BO, we removed any effect of selective survival bias, disease severity ${ }^{41}$ or time window bias, ${ }^{42}$ as those patients with $\mathrm{BO}$ with a longer follow-up are more likely to develop HGD or OAC. By doing so, observing any spurious associations was avoided. Second, we mitigated against immortal time bias ${ }^{43}$ by defining the exposure period from $\mathrm{BO}$ diagnosis up to matching date, thus avoiding an overestimation of the preventive effect. The estimates from our study are likely more generalisable to the daily clinical practice in the general population, also including patients with less severe $\mathrm{BO}$, that is, those with a shorter $\mathrm{BO}$ segment. A potential preventive effect of NSAIDs might therefore only be observed within selected high-risk subgroups. 
Table 3 Risk of OAC and HGD-OAC by drug class by duration on data pooled on patient-level

\begin{tabular}{|c|c|c|c|c|c|c|c|c|c|c|c|c|c|}
\hline \multirow[b]{2}{*}{ Exposure } & \multirow[b]{2}{*}{$\begin{array}{l}\text { Duration } \\
\text { category }\end{array}$} & \multicolumn{6}{|l|}{ OAC } & \multicolumn{6}{|c|}{ HGD-OAC } \\
\hline & & $\begin{array}{l}\text { OAC } \\
\text { Case } \\
\mathrm{N}(\%) \\
\end{array}$ & $\begin{array}{l}\text { OAC } \\
\text { Control } \\
\text { N (\%) }\end{array}$ & $\begin{array}{l}\text { ORmatched } \\
(95 \% \mathrm{Cl})\end{array}$ & $\begin{array}{l}p \\
\text { Value }\end{array}$ & $\begin{array}{l}\text { ORadjusted* } \\
\text { (95\% Cl) }\end{array}$ & $\begin{array}{l}p \\
\text { Value }\end{array}$ & $\begin{array}{l}\text { Case } \\
\mathrm{N}(\%)\end{array}$ & $\begin{array}{l}\text { Control } \\
\text { N (\%) }\end{array}$ & $\begin{array}{l}\text { ORmatched } \\
(95 \% \mathrm{Cl})\end{array}$ & $\begin{array}{l}p \\
\text { Value }\end{array}$ & $\begin{array}{l}\text { ORadjusted* } \\
(95 \% \mathrm{Cl})\end{array}$ & $\begin{array}{l}\mathbf{p} \\
\text { Value }\end{array}$ \\
\hline Total & & $45(100)$ & $732(100)$ & & & & & $57(100)$ & 1409 (100) & & & & \\
\hline \multirow[t]{5}{*}{ NSAID } & None & $32(71)$ & $566(77)$ & Ref & & Ref & & $44(77)$ & $1159(82)$ & Ref & & Ref & \\
\hline & Yes & $13(29)$ & $166(23)$ & $1.3(0.6$ to 2.5$)$ & 0.492 & $1.2(0.6$ to 2.5$)$ & 0.532 & $13(23)$ & 250 (18) & $1.0(0.5$ to 1.9$)$ & 1.000 & $0.9(0.5$ to 1.8$)$ & 0.876 \\
\hline & $\leq 1$ months & $6(11)$ & $65(9)$ & 1.4 (0.6 to 3.6$)$ & 0.454 & 1.4 (0.6 to 3.5$)$ & 0.471 & $6(11)$ & $121(9)$ & 1.1 (0.4 to 2.6$)$ & 0.882 & $1.0(0.4$ to 2.5$)$ & 0.967 \\
\hline & $\begin{array}{l}>1 \text { months to } \\
1 \text { year }\end{array}$ & $5(9)$ & 72 (10) & $1.2(0.4$ to 3.1$)$ & 0.768 & 1.1 (0.4 to 3.0$)$ & 0.817 & $5(9)$ & $98(7)$ & 0.9 (0.3 to 2.4) & 0.836 & 0.8 (0.3 to 2.3$)$ & 0.737 \\
\hline & $>1$ year & $2(4)$ & $29(4)$ & $1.2(0.3$ to 5.3$)$ & 0.837 & 1.1 (0.3 to 5.2$)$ & 0.859 & $2(4)$ & $31(2)$ & $1.1(0.2$ to 4.7$)$ & 0.934 & $1.0(0.2$ to 4.6$)$ & 0.970 \\
\hline \multirow[t]{7}{*}{ Statins } & None & $33(73)$ & $479(65)$ & Ref & & Ref & & $42(74)$ & $1050(75)$ & Ref & & Ref & \\
\hline & Yes & $12(27)$ & $253(35)$ & $0.8(0.4$ to 1.5$)$ & 0.432 & 0.7 (0.4 to 1.5$)$ & 0.412 & $15(26)$ & 359 (25) & $0.9(0.5$ to 1.7$)$ & 0.720 & $0.9(0$ & 0.673 \\
\hline & $\leq 1$ months & $1(2)$ & $6(1)$ & $2.1(0.2$ to 20.4$)$ & 0.511 & 2.0 (0.2 to 20.1$)$ & 0.561 & $1(2)$ & $7(0)$ & $2.2(0.2$ to 20.6$)$ & 0.487 & $0.5)$ & 0.520 \\
\hline & $\begin{array}{l}>1 \text { months to } \\
1 \text { year }\end{array}$ & $3(7)$ & $62(8)$ & 0.9 (0.3 to 3.2) & 0.908 & $1.0(0.3$ to 3.4$)$ & 0.971 & $4(7)$ & $128(9)$ & 0.9 (0.3 to 2.8$)$ & 0.914 & $1.0(0.3$ to 2.8$)$ & 0.951 \\
\hline & $>1$ to 2 years & $4(9)$ & $66(9)$ & 0.9 (0.3 to 2.7$)$ & 0.848 & 0.9 & 4 & $5(9)$ & (6) & 1.1( & 0.868 & 1. & 0.907 \\
\hline & $>2$ to 3 years & $1(2)$ & $30(4)$ & 0.6 (0.1 to 4.9$)$ & 0.651 & 0.6 (0.1 to 4.7$)$ & 0.629 & $2(4)$ & $41(3)$ & 1.2 (0.3 to 5.3$)$ & .828 & 1.1 (0.2 to 4.9$)$ & 0.897 \\
\hline & $>3$ years & $3(7)$ & $89(12)$ & 0.5 (0.1 to 1.7$)$ & 0.259 & 0.5 (0.1 to 1.7$)$ & 0.239 & $3(5)$ & $93(7)$ & 0.5 (0.1 to 1.8$)$ & 0.276 & 0.5 (0.1 to 1.7$)$ & 0.253 \\
\hline \multirow[t]{5}{*}{ PPIs } & 0 to $\leq 6$ months & $5(11)$ & $103(14)$ & Ref & & Ref & & $11(19)$ & $450(32)$ & Ref & & Ref & \\
\hline & Yes & $40(89)$ & $629(86)$ & 1.1 (0.4 to 3.0$)$ & 0.814 & $1.1(0.4$ to 2.8$)$ & 0.911 & $46(81)$ & 959 (68) & 1.0 (0.5 to 2.2$)$ & 0.917 & 0.9 (0.4 to 2.0$)$ & 0.855 \\
\hline & $\begin{array}{l}>6 \text { to } \\
\leq 12 \text { months }\end{array}$ & $6(13)$ & $169(23)$ & 1.9 (0.5 to 6.6$)$ & 0.502 & $2.0(0.5$ to 7.0$)$ & 0.299 & $7(12)$ & $158(11)$ & 1.7 (0.6 to 4.6$)$ & 0.293 & 1.7 (0.6 to 4.5$)$ & 0.312 \\
\hline & $\begin{array}{l}>12 \text { to } \\
\leq 24 \text { months }\end{array}$ & $9(20)$ & $151(21)$ & $1.8(0.6$ to 5.4$)$ & 0.672 & 1.7 (0.6 to 5.3$)$ & 0.328 & $10(18)$ & 227 (16) & 1.7 (0.7 to 4.2$)$ & 0.255 & 1.6 (0.6 to 3.9$)$ & 0.326 \\
\hline & $>24$ months & $5(11)$ & $162(22)$ & $2.1(0.8$ to 5.6$)$ & 0.476 & 1.9 (0.7 to 5.2$)$ & 0.207 & $27(47)$ & 377 (27) & 1.7 (0.7 to 4.0$)$ & 0.204 & 1.5 (0.7 to 3.6$)$ & 0.327 \\
\hline \multirow[t]{5}{*}{ SSRIS } & None & $40(89)$ & $679(93)$ & Ref & & Ref & & $52(91)$ & 1344 (95) & Ref & & Ref & \\
\hline & Yes & $5(11)$ & $53(7)$ & 1.7 (0.6 to 4.7$)$ & 0.281 & 1.7 (0.6 to 4.6$)$ & 0.310 & $5(9)$ & $65(5)$ & 1.6 (0.6 to 4.2$)$ & 0.356 & $1.5(C$ & 0.390 \\
\hline & $\leq 1$ months & $0(0)$ & $3(0)$ & - & 0.992 & - & 0.992 & $0(0)$ & $3(0)$ & - & 0.988 & - & 0.988 \\
\hline & $\begin{array}{l}>1 \text { months to } \\
1 \text { year }\end{array}$ & $3(7)$ & $23(3)$ & 2.6 (0.7 to 9.2) & 0.142 & 2.5 (0.7 to 8.9$)$ & 0.155 & $3(5)$ & $28(2)$ & $2.4(0.7$ to 8.6$)$ & 0.165 & 2.4 (0.7 to 8.4$)$ & 0.175 \\
\hline & $>1$ year & $2(4)$ & $27(4)$ & $1.2(0.3$ to 5.5$)$ & 0.778 & $1.2(0.3$ to 5.4$)$ & 0.815 & $2(4)$ & $34(2)$ & $1.1(0.2$ to 4.9$)$ & 0.888 & $1.1(0.2$ to 4.7$)$ & 0.931 \\
\hline \multirow{5}{*}{$\begin{array}{l}\text { Low-dose } \\
\text { aspirin }\end{array}$} & None & $35(78)$ & $553(76)$ & Ref & & Ref & & $46(81)$ & $1189(84)$ & Ref & & Ref & \\
\hline & Yes & $10(22)$ & $179(24)$ & 0.9 (0.4 to 1.8$)$ & 0.702 & 0.8 (0.4 to 1.8$)$ & 0.662 & $11(19)$ & $220(16)$ & 0.9 (0.4 to 1.9$)$ & 0.799 & 0.9 (0.4 to 1.8$)$ & 0.764 \\
\hline & $\leq 6$ months & $2(4)$ & $33(5)$ & 1.0 (0.2 to 4.2$)$ & 0.954 & $1.0(0.2$ to 4.3$)$ & 0.970 & $2(4)$ & $49(3)$ & 0.9 (0.2 to 3.7$)$ & 0.840 & $0.9(0.2$ to 3.8$)$ & 0.847 \\
\hline & $\begin{array}{l}>6 \text { months to } \\
1 \text { year }\end{array}$ & $0(0)$ & $26(4)$ & - & & - & & $1(2)$ & $36(3)$ & - & & - & \\
\hline & $>1$ year & $8(18)$ & $120(16)$ & 1.0 (0.4 to 2.2$)$ & 0.920 & 0.9 (0.4 to 2.1$)$ & 0.844 & $8(14)$ & $135(10)$ & 0.9 (0.4 to 2.1$)$ & 0.867 & 0.9 (0.4 to 2.1$)$ & 0.805 \\
\hline
\end{tabular}

${ }^{*}$ Adjusted for duration of follow-up since BO diagnosis.

Cumulative use of drugs considered continuously (OR represents the change per day additional use).

BO, Barrett's oesophagus; HGD, high-grade dysplasia; NSAID, non-steroidal anti-inflammatory drugs; PPIs, proton pump inhibitors; OAC, oesophageal adenocarcinoma; SSRIs, selective

serotonin re-uptake inhibitors. 
Table 4 Risk of OAC and HGD-OAC by drug class by daily dose on data pooled on patient-level

\begin{tabular}{|c|c|c|c|c|c|c|c|c|c|}
\hline \multirow[b]{2}{*}{ Drug exposure } & \multirow[b]{2}{*}{ Dose category } & \multicolumn{4}{|c|}{ OAC only } & \multicolumn{4}{|c|}{ HGD-OAC } \\
\hline & & $\begin{array}{l}\text { Case } \\
\text { N (\%) }\end{array}$ & $\begin{array}{l}\text { Control } \\
\text { N (\%) }\end{array}$ & $\begin{array}{l}\text { ORmatched } \\
(95 \% \mathrm{Cl})\end{array}$ & p Value & $\begin{array}{l}\text { Case } \\
\text { N (\%) }\end{array}$ & $\begin{array}{l}\text { Control } \\
\text { N (\%) }\end{array}$ & $\begin{array}{l}\text { ORmatched } \\
(95 \% \mathrm{Cl})\end{array}$ & p Value \\
\hline Total & & $45(100)$ & $732(100)$ & & & $57(100)$ & $1409(100)$ & & \\
\hline \multirow[t]{4}{*}{ NSAID } & None & $32(71)$ & $566(77)$ & Ref & - & $44(77)$ & $1159(82)$ & Ref & - \\
\hline & $<0.8$ DDD per day & $3(7)$ & $39(5)$ & $1.1(0.3$ to 3.7$)$ & 0.909 & $3(5)$ & $107(8)$ & 0.6 (0.2 to 2.2$)$ & 0.475 \\
\hline & $\geq 0.8$ to $<1.2$ DDD per day & $4(9)$ & $74(10)$ & 0.9 (0.3 to 2.5$)$ & 0.783 & $4(7)$ & $84(6)$ & 0.8 (0.3 to 2.3$)$ & 0.633 \\
\hline & $\geq 1.2$ DDD per day & $6(13)$ & $53(7)$ & $2.2(0.8$ to 5.6$)$ & 0.111 & $6(11)$ & $59(4)$ & $1.9(0.8$ to 5.0$)$ & 0.160 \\
\hline \multirow[t]{4}{*}{ Statin } & None & $33(73)$ & $479(65)$ & Ref & - & $42(74)$ & $1050(75)$ & Ref & - \\
\hline & $<0.8$ DDD per day & $8(18)$ & $126(17)$ & 0.9 (0.4 to 2.2$)$ & 0.880 & $9(16)$ & $174(12)$ & $1.0(0.5$ to 2.1$)$ & 0.959 \\
\hline & $\geq 0.8$ to $<1.2$ DDD per day & $1(2)$ & $49(7)$ & 0.3 (0.05 to 2.6$)$ & 0.305 & $2(4)$ & $62(4)$ & 0.7 (0.2 to 3.1$)$ & 0.637 \\
\hline & $\geq 1.2$ DDD per day & $3(7)$ & $78(11)$ & $0.7(0.2$ to 2.3$)$ & 0.519 & $4(7)$ & $123(9)$ & $0.8(0.3$ to 2.4$)$ & 0.731 \\
\hline \multirow[t]{4}{*}{ PPI } & None & $5(11)$ & $103(14)$ & Ref & - & $11(19)$ & $450(32)$ & Ref & - \\
\hline & $<0.8$ DDD per day & $9(20)$ & $168(23)$ & $0.9(0.3$ to 3.0$)$ & 0.914 & $11(19)$ & $196(14)$ & $1.1(0.4$ to 2.8$)$ & 0.910 \\
\hline & $\geq 0.8$ to $<1.2$ DDD per day & $23(51)$ & $315(43)$ & $1.2(0.4$ to 3.4$)$ & 0.723 & $27(47)$ & 454 (32) & 1.1 (0.5 to 2.6$)$ & 0.768 \\
\hline & $\geq 1.2$ DDD per day & $8(18)$ & $146(20)$ & $1.1(0.4$ to 3.6$)$ & 0.822 & $8(14)$ & $309(22)$ & $0.9(0.3$ to 2.3$)$ & 0.813 \\
\hline \multirow[t]{4}{*}{ SSRI } & None & $40(89)$ & $679(93)$ & Ref & - & $52(91)$ & $1344(95)$ & Ref & - \\
\hline & $<0.8$ DDD per day & $1(2)$ & $8(1)$ & $3.0(0.4$ to 25.4$)$ & 0.317 & $1(2)$ & $8(1)$ & $3(0.3$ to 25.1$)$ & 0.321 \\
\hline & $\geq 0.8$ to $<1.2$ DDD per day & $4(9)$ & $32(4)$ & $2.3(0.7$ to 7.1$)$ & 0.149 & $4(7)$ & $44(3)$ & $2.0(0.7$ to 6.0$)$ & 0.218 \\
\hline & $\geq 1.2$ DDD per day & $0(0)$ & $13(2)$ & - & 0.987 & $0(0)$ & $13(1)$ & - & 0.987 \\
\hline
\end{tabular}

DDD, defined daily dose; HGD, high-grade dysplasia; NSAID, non-steroidal anti-inflammatory drugs; OAC, oesophageal adenocarcinoma; PPIs, proton pump inhibitors; SSRIs, selective serotonin re-uptake inhibitors.

Table 5 Risk of OAC and HGD-OAC for concomitant drug exposure of NSAIDs, LDA, statins and PPIs

\section{OAC only}

\begin{tabular}{|c|c|c|c|c|c|c|c|c|c|c|c|c|}
\hline \multirow[b]{2}{*}{$\begin{array}{l}\text { Drug } \\
\text { exposure* }\end{array}$} & \multicolumn{6}{|c|}{ UAC onIy } & \multicolumn{6}{|c|}{ HGD-OAC } \\
\hline & $\begin{array}{l}\text { Case } \\
\text { N (\%) }\end{array}$ & $\begin{array}{l}\text { Control } \\
\text { N (\%) }\end{array}$ & $\begin{array}{l}\text { ORmatched } \\
(95 \% \mathrm{Cl})\end{array}$ & $\begin{array}{l}p \\
\text { Value }\end{array}$ & $\begin{array}{l}\text { ORadjusted } \\
\text { model† } \\
(95 \% \mathrm{Cl})\end{array}$ & $\begin{array}{l}p \\
\text { Value }\end{array}$ & $\begin{array}{l}\text { Case } \\
\mathrm{N}(\%)\end{array}$ & $\begin{array}{l}\text { Control } \\
\mathrm{N}(\%)\end{array}$ & $\begin{array}{l}\text { ORmatched } \\
(95 \% \mathrm{Cl})\end{array}$ & $\begin{array}{l}p \\
\text { Value }\end{array}$ & $\begin{array}{l}\text { ORadjusted } \\
\text { model† }(95 \% \mathrm{Cl})\end{array}$ & $\begin{array}{l}\text { p } \\
\text { Value }\end{array}$ \\
\hline Total & 45 (100) & $732(100)$ & & & & & $57(100)$ & $1409(100)$ & & & & \\
\hline PPI only & $19(42)$ & $284(39)$ & Ref & - & Ref & - & $22(39)$ & $441(31)$ & Ref & - & Ref & - \\
\hline $\begin{array}{l}\text { No NSAID or } \\
\text { LDA or statin or } \\
\text { PPI }\end{array}$ & $3(7)$ & $65(9)$ & 0.9 (0.2 to 3.2$)$ & 0.837 & 0.9 (0.3 to 3.4$)$ & 0.919 & $9(16)$ & 407 (29) & $1.0(0.4$ to 2.4$)$ & 0.947 & $1.1(0.4$ to 2.8$)$ & 0.839 \\
\hline NSAID+PPI & $6(13)$ & $72(10)$ & 1.2 (0.5 to 3.2$)$ & 0.700 & $1.1(0.4$ to 3.0$)$ & 0.773 & $6(11)$ & $124(9)$ & 0.9 (0.4 to 2.4$)$ & 0.898 & 0.9 (0.3 to 2.2$)$ & 0.774 \\
\hline Statin+PPI & $5(11)$ & 85 (12) & $1.0(0.4$ to 2.9$)$ & 0.963 & 1.0 (0.3 to 2.8$)$ & 0.988 & $7(12)$ & $143(10)$ & $1.2(0.5$ to 3.1$)$ & 0.630 & $1.2(0.5$ to 3.0$)$ & 0.674 \\
\hline LDA+PPI & $3(7)$ & $30(4)$ & $1.4(0.4$ to 5.5$)$ & 0.597 & 1.3 (0.4 to 5.2$)$ & 0.655 & $3(5)$ & $42(3)$ & 1.3 (0.4 to 4.9$)$ & 0.691 & $1.2(0.3$ to 4.7$)$ & 0.742 \\
\hline $\mathrm{LDA}+\mathrm{PPI}+$ statin & & & & & & & $2(4)$ & $104(7)$ & $0.4(0.1$ to 1.7$)$ & 0.202 & $0.4(0.1$ to 1.7$)$ & 0.198 \\
\hline $\begin{array}{l}\text { NSAID+LDA } \\
\text { +statin+PPI }\end{array}$ & $4(9)$ & $41(6)$ & 1.2 (0.4 to 3.8$)$ & 0.744 & $1.2(0.4$ to 3.8$)$ & 0.760 & $4(7)$ & $43(3)$ & 1.2 (0.4 to 3.9$)$ & 0.727 & $1.2(0.4$ to 3.8$)$ & 0.745 \\
\hline
\end{tabular}

${ }^{*}$ Numbers do not add up due to drug exposure categories with only one exposed case, not shown in the Table.

$\dagger$ Adjusted for duration of follow-up since BO diagnosis.

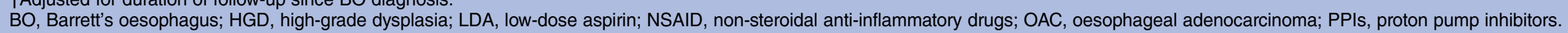


Third, the inability to show a significant decrease in HGD and OAC risk for drug use may be explained by the distinct exposure definition that we applied. Contrasting with others, ${ }^{13}{ }^{40}$ we classified exposure cumulatively and performed dose-duration analyses rather than assessing drug exposure at a single moment. This, however, also limited the analyses by creating multiple exposure categories. Drug exposure changes over time, especially in the long time taken to develop cancer. Assessment of exposure on a fixed moment will result in bias that exaggerates the effect downwards, showing a protective effect while actually it has no effect. ${ }^{42} \mathrm{~A}$ pooled analysis of observational studies demonstrated an inverse association between the risk of HGD-OAC and use of NSAIDs. ${ }^{24}$ A prospective cohort study also showed a decreased HR of HGD-OAC for use of NSAIDs and statins, however, the study results were influenced by immortal time bias. ${ }^{17} 44$ In that study, the majority of cases included HGD cases. In line with the other Dutch study, ${ }^{17}$ when we included HGD cases the risk of HGD-OAC was lower than when including OAC cases only. The preventive effect is possibly achieved in the premalignant stage of dysplasia-development rather than that of adenocarcinoma. It is, however, difficult to disentangle drug exposure effects in three different risk periods: induction (dysplasia), latent (between dysplasia and cancer) and disease period (cancer). Ideally, this requires knowledge on exact timing of the first aberrant Barrett's cell and subsequent stages towards HGD and OAC progression develop.

The fourth explanation for not observing a preventive effect may be the exposure prevalence. Regarding NSAID exposure prevalence, we could not capture over-thecounter use of NSAIDs. During the study period, NSAIDs and PPIs were reimbursable in the NL and the UK, and thus we assume that over-the-counter use of NSAIDs and PPIs did not confound the results to a great extent. Prevalence of PPI $(81 \%)$ and statin (26\%) exposure in our study is, however, comparable with other studies and is therefore unlikely to have limited our power. ${ }^{1745}$

A large prospective US cohort study showed a tremendous protective effect of NSAIDs on OAC risk. ${ }^{40}$ However, NSAID exposure was assessed in a personal interview and classified very broadly by NSAIDs used at least once a week for 6 months. ${ }^{40}$ If the preventive effect of NSAIDs were as high as reported (up to 80\%), a duration-dose-response effect is to be expected. This study failed to demonstrate an inverse association between duration of NSAID use and the risk of OAC. In fact, the opposite was observed; the most protective effect was seen for the shortest duration, ${ }^{40}$ contradicting a causal association. ${ }^{27}{ }^{46} \mathrm{~A}$ pooled analysis also could not demonstrate that prolonged duration of NSAID use was associated with a lower risk of OAC. ${ }^{24}$ Additionally, heterogeneity between studies was observed, ${ }^{24}$ which emphasises the controversy around clinically effective chemoprevention with NSAIDs.

The preventive effect of statins is shown in several studies, ${ }^{13} 17$ yielding a risk reduction of OAC up to $48 \%$ for statin use $>1$ year. ${ }^{15}$ However, in a meta-analysis, the risk reduction of $\mathrm{OAC}$ among patients with $\mathrm{BO}$ was only seen when studies were included that assessed drug exposure by patient interview, which may be prone to recall bias, whereas the risk reduction was not significant, including studies that assessed drug exposure by use of prescription/dispensing data in electronic medical records. ${ }^{26}$ Also, for statins, the most pronounced effect was seen when HGD was included. ${ }^{16}$ Results from the latter study should be interpreted with caution as drug exposure was classified by self-report as 'ever' instead of a duration classification. A recent casecontrol study, using a GP database from the UK, showed that statins may also decrease the risk of OAC and oesophagogastric junctional adenocarcinoma in the general population. ${ }^{47}$ The chemopreventive action of statins was more pronounced when combined with low-dose aspirin in a previous study. ${ }^{13}$ It could be that the preventive effect of statins is explained by other risk factors common to statin users and patients with OAC, such as cardiovascular risk factors or lifestyle changes: smoking, exercise and weight. ${ }^{47}$ Also it may be that patients with $\mathrm{BO}$ died from vascular diseases rather than of cancerrelated causes or before HGD or OAC developed. ${ }^{48}$ In our study, statin users were less likely to be current smokers, were of older age and were more often men. However, whether lifestyle changes due to comorbid cardiovascular diseases and initiating statin therapy may have resulted in healthier behaviour, and subsequent OAC risk reduction, is open to debate.

Strengths of the current study include the scale and setting by combining healthcare data from two European countries with comparable GP databases and applying a common study protocol and drug exposure definition. The nested case-control design in a welldefined population representing the general population minimised selection bias. While previous studies may have suffered from recall bias or the lack of detailed drug prescription data, we were able to estimate the risk of HGD and OAC within patients with BO during drug use in the general population. Although our analysis may be limited by the small number of cases in the dose-duration analyses, partly due to the fact that we only included incident cases (diagnosed $\geq 1$ year after BO diagnosis), our study is unlikely to suffer from biases (immortal time bias, time window bias) and confounding (disease severity) by matching on important risk factors. Matched and adjusted analyses were in line with each other suggesting that there was little confounding.

A limitation of the study is the lack of detailed pathology information on the Barrett segment length and grade of dysplasia, as is current practice for risk stratification of patients with BO. This may have resulted in misclassification of $\mathrm{BO}$ and $\mathrm{OAC}$. However, the 1-year risk of OAC after BO diagnosis, excluding OAC cases within 1 year after BO diagnosis, was $0.086 \%$ (95\% CI 0.04 to 0.17 ) in the current study, ${ }^{10}$ which is similar to other population-based studies. ${ }^{4}{ }^{49}{ }^{50}$ Because we could not verify the diagnosis of $\mathrm{BO}$ against a clinical prespecified 
standard and did not review biopsy specimens, it is also possible that we inadvertently included patients at very low risk of developing OAC. In the Dutch database, we could search through the medical records and noted that $8 \%$ had a segment length $<2 \mathrm{~cm}, 13.7 \%$ between 2 and $3 \mathrm{~cm}, 11.8 \%$ longer than $3 \mathrm{~cm}$, whereas for $60 \%$ of BO controls the length was not mentioned. Regarding the grade of dysplasia at time of $\mathrm{BO}$ diagnosis, $45 \%$ of controls had no dysplasia; there was low grade dysplasia in $6 \%$ of patients with $\mathrm{BO}$, indefinite for dysplasia in $1.8 \%$, whereas no information on dysplasia grade was available in $46 \%$ of controls. Of the cases that developed HGD or OAC, $24 \%$ had a prior histology report of lowgrade dysplasia. In the Dutch database we could utilise all free text entered in the medical record, enabling us to look for more detailed information in clinical letters, resulting in higher proportion of risk factors, such as presence of oesophagitis and a hiatal hernia at time of BO diagnosis as compared with the UK database, in which we relied on diagnosis codes. We tried to address confounding-by-indication and time-window bias by matching on age, sex and year of BO diagnosis. ${ }^{42}$ This is seen by the fact that individual risk factors did not increase the OAC risk and adjustment for these confounders did not change the estimate by $\geq 10 \%$. The observation that PPIs appear to increase the risk of OAC is explained by the treatment indication being a risk factor for OAC, reverse causation and the phenomenon of 'channeling', where high-risk patients are being prescribed PPIs whereas low-risk patients are being prescribed with lower doses or not at all, ${ }^{15} \quad 224751 \quad 52$ a phenomenon often seen with PPIs and upper gastrointestinal bleeding. ${ }^{53}$ It could also be that the effect of PPIs is apparent after minimally 2 years of use,${ }^{15} 20$ an observation that was not significant in our study.

In conclusion, in this population-based nested casecontrol study, use of NSAIDs, PPIs, low-dose aspirin or statins did not reduce the risk of HGD and OAC among patients with BO. These findings indicate that for an unselected group of patients with $\mathrm{BO}$, chemoprevention by use of drug to reduce progression should not be considered directly as routine care.

\section{Author affiliations}

${ }^{1}$ Department of Medical Informatics, Erasmus University Medical Center, Rotterdam, The Netherlands

${ }^{2}$ Department of Gastroenterology and Hepatology, Erasmus University Medical Center, Rotterdam, The Netherlands

${ }^{3}$ Department of Epidemiology, Erasmus University Medical Center, Rotterdam, The Netherlands

Contributors GMCM contributed to study concept and design; acquisition of data; analysis and interpretation of data; statistical analysis; drafting of the manuscript. PMC contributed to study concept and design; interpretation of data; drafting of the manuscript. MCWS contributed to critical revision of the manuscript for important intellectual content. EJK contributed to analysis and interpretation of data; critical revision of the manuscript for important intellectual content MCJMS contributed to study concept and design; acquisition of data; analysis and interpretation of data; critical revision of the manuscript for important intellectual content; obtained funding; study supervision. All authors approved the final version of the manuscript.
Funding This research received no specific grant from any funding agency in the public, commercial or not-for-profit sectors.

Competing interests EJK has, since completion of this research, started working for the medical board of Erasmus University Medical Center. MCJMS is coordinating a research group that has unconditional research grants from Pfizer, Novartis and Lilly; none related to this research.

Ethics approval The Scientific and Ethical Advisory Boards of both databases (THIN and IPIC) approved the study.

Provenance and peer review Not commissioned; externally peer reviewed.

Data sharing statement No additional data are available.

Open Access This is an Open Access article distributed in accordance with the Creative Commons Attribution Non Commercial (CC BY-NC 4.0) license, which permits others to distribute, remix, adapt, build upon this work noncommercially, and license their derivative works on different terms, provided the original work is properly cited and the use is non-commercial. See: http:// creativecommons.org/licenses/by-nc/4.0/

\section{REFERENCES}

1. Spechler SJ, Souza RF. Barrett's esophagus. N Engl J Med 2014;371:836-45.

2. Wang KK, Sampliner RE. Updated guidelines 2008 for the diagnosis, surveillance and therapy of Barrett's esophagus. Am J Gastroenterol 2008;103:788-97.

3. Solaymani-Dodaran M, Logan RF, West J, et al. Risk of oesophageal cancer in Barrett's oesophagus and gastro-oesophageal reflux. Gut 2004:53:1070-4.

4. de Jonge PJ, van Blankenstein M, Looman CW, et al. Risk of malignant progression in patients with Barrett's oesophagus: a Dutch nationwide cohort study. Gut 2010;59:1030-6.

5. Desai TK, Krishnan K, Samala N, et al. The incidence of oesophageal adenocarcinoma in non-dysplastic Barrett's oesophagus: a meta-analysis. Gut 2012;61:970-6.

6. Globocan 2008 Worldwide Cancer Incidence M, Prevalence and Disability-adjusted life years (DALYs) (accessed 11 Jul 2014)

7. Yousef F, Cardwell C, Cantwell MM, et al. The incidence of esophageal cancer and high-grade dysplasia in Barrett's esophagus: a systematic review and meta-analysis. Am J Epidemiol 2008;168:237-49.

8. Sikkema M, de Jonge PJ, Steyerberg EW, et al. Risk of esophageal adenocarcinoma and mortality in patients with Barrett's esophagus: a systematic review and meta-analysis. Clin Gastroenterol Hepatol 2010;8:235-44; quiz e32.

9. Rastogi A, Puli S, El-Serag HB, et al. Incidence of esophageal adenocarcinoma in patients with Barrett's esophagus and high-grade dysplasia: a meta-analysis. Gastrointest Endosc 2008;67:394-8.

10. Masclee GM, Coloma PM, de Wilde M, et al. The incidence of Barrett's oesophagus and oesophageal adenocarcinoma in the United Kingdom and the Netherlands is levelling off. Aliment Pharmacol Ther 2014;39:1321-30.

11. WHO Global Health Observatory Data Repository. Cause-specific mortality, 2008: WHO region by country. http://apps.who.int/gho/ data/node.main.887?lang=en (accessed 18 Oct 2013).

12. Cancer Research UK. Oesophageal cancer survival statistics. http:// www.cancerresearchuk.org/cancer-info/cancerstats/types/ oesophagus/survival/\#Trends (accessed 18 Oct 2013).

13. Beales IL, Vardi I, Dearman L. Regular statin and aspirin use in patients with Barrett's oesophagus is associated with a reduced incidence of oesophageal adenocarcinoma. Eur J Gastroenterol Hepatol 2012;24:917-23.

14. Corley DA, Kerlikowske K, Verma R, et al. Protective association of aspirin/NSAIDs and esophageal cancer: a systematic review and meta-analysis. Gastroenterology 2003;124:47-56.

15. Nguyen DM, Richardson P, El-Serag HB. Medications (NSAIDs, statins, proton pump inhibitors) and the risk of esophageal adenocarcinoma in patients with Barrett's esophagus. Gastroenterology 2010;138:2260-6.

16. Kantor ED, Onstad L, Blount PL, et al. Use of statin medications and risk of esophageal adenocarcinoma in persons with Barrett's esophagus. Cancer Epidemiol Biomarkers Prev 2012;21:456-61.

17. Kastelein F, Spaander MC, Biermann K, et al. Nonsteroidal anti-inflammatory drugs and statins have chemopreventative effects in patients with Barrett's esophagus. Gastroenterology 2011;141:2000-8; quiz e13-4. 
18. Abnet CC, Freedman ND, Kamangar F, et al. Non-steroidal anti-inflammatory drugs and risk of gastric and oesophageal adenocarcinomas: results from a cohort study and a meta-analysis. Br J Cancer 2009;100:551-7.

19. Rothwell PM, Fowkes FG, Belch JF, et al. Effect of daily aspirin on long-term risk of death due to cancer: analysis of individual patient data from randomised trials. Lancet 2011;377:31-41.

20. Singh S, Garg SK, Singh PP, et al. Acid-suppressive medications and risk of oesophageal adenocarcinoma in patients with Barrett's oesophagus: a systematic review and meta-analysis. Gut 2014;63:1229-37.

21. Sivarasan N, Smith G. Role of aspirin in chemoprevention of esophageal adenocarcinoma: a meta-analysis. J Dig Dis 2013;14:222-30.

22. Garcia Rodriguez LA, Lagergren J, Lindblad M. Gastric acid suppression and risk of oesophageal and gastric adenocarcinoma: a nested case control study in the UK. Gut 2006;55:1538-44.

23. Zhang S, Zhang XQ, Ding XW, et al. Cyclooxygenase inhibitors use is associated with reduced risk of esophageal adenocarcinoma in patients with Barrett's esophagus: a meta-analysis. $\mathrm{Br} \mathrm{J}$ Cancer 2014:110:2378-88.

24. Liao LM, Vaughan TL, Corley DA, et al. Nonsteroidal anti-inflammatory drug use reduces risk of adenocarcinomas of the esophagus and esophagogastric junction in a pooled analysis. Gastroenterology 2012;142:442-52.e5; quiz e22-3.

25. Nguyen T, Khalaf N, Ramsey D, et al. Statin use is associated with a decreased risk of Barrett's esophagus. Gastroenterology 2014; 147:314-23.

26. Singh S, Singh AG, Singh PP, et al. Statins are associated with reduced risk of esophageal cancer, particularly in patients with Barrett's esophagus: a systematic review and meta-analysis. Clin Gastroenterol Hepatol 2013;11:620-9.

27. Rothman KJ, Greenland S, Lash TL. Causation and causal inference. Modern epidemiology. 3rd edn. Philadelphia: Lippincott Williams \& Wilkins, 2008

28. Lewis JD, Schinnar R, Bilker WB, et al. Validation studies of the health improvement network (THIN) database for pharmacoepidemiology research. Pharmacoepidemiol Drug Saf 2007; 16:393-401.

29. Vlug AE, van der Lei J, Mosseveld BM, et al. Postmarketing surveillance based on electronic patient records: the IPCI project. Methods Inf Med 1999;38:339-44.

30. Booth N. What are the read codes? Health Libr Rev 1994;11:177-82.

31. Lamberts $\mathrm{H}$, Wood M, Hofmans-Okkes IM. International primary care classifications: the effect of fifteen years of evolution. Fam Pract 1992;9:330-9.

32. WHO Collaborating Centre for Drug Statistics Methodology. Guidelines for ATC classification and DDD assignment. http://www. whocc.no/atcddd/ (accessed 4 Apr 2013).

33. Wilson KT, Fu S, Ramanujam KS, et al. Increased expression of inducible nitric oxide synthase and cyclooxygenase-2 in Barrett's esophagus and associated adenocarcinomas. Cancer Res 1998;58:2929-34

34. Buttar NS, Wang KK, Anderson MA, et al. The effect of selective cyclooxygenase-2 inhibition in Barrett's esophagus epithelium: an in vitro study. J Natl Cancer Inst 2002;94:422-9.
35. Falk GW, Buttar NS, Foster NR, et al. A combination of esomeprazole and aspirin reduces tissue concentrations of prostaglandin $\mathrm{E}(2)$ in patients with Barrett's esophagus. Gastroenterology 2012;143:917-26.e1.

36. Lochhead P, Chan AT. Statins and colorectal cancer. Clin Gastroenterol Hepatol 2013;11:109-18; quiz e13-4.

37. Ogunwobi OO, Beales IL. Statins inhibit proliferation and induce apoptosis in Barrett's esophageal adenocarcinoma cells. Am J Gastroenterol 2008;103:825-37.

38. Sadaria MR, Reppert AE, Yu JA, et al. Statin therapy attenuates growth and malignant potential of human esophageal adenocarcinoma cells. J Thorac Cardiovasc Surg 2011;142: 1152-60.

39. Konturek PC, Burnat G, Hahn EG. Inhibition of Barret's adenocarcinoma cell growth by simvastatin: involvement of COX-2 and apoptosis-related proteins. J Physiol Pharmacol 2007;58(Suppl 3):141-8.

40. Vaughan TL, Dong LM, Blount PL, et al. Non-steroidal anti-inflammatory drugs and risk of neoplastic progression in Barrett's oesophagus: a prospective study. Lancet Oncol 2005;6:945-52.

41. Delgado-Rodriguez M, Llorca J. Bias. J Epidemiol Community Health 2004;58:635-41.

42. Suissa S, Dell'aniello $S$, Vahey $S$, et al. Time-window bias in case-control studies: statins and lung cancer. Epidemiology 2011;22:228-31.

43. Suissa $\mathrm{S}$. Immortal time bias in pharmaco-epidemiology. Am J Epidemiol 2008;167:492-9.

44. Azoulay L, Suissa S. Immortal person-time bias in relation to the use of nonsteroidal anti-inflammatory drugs and statins in the prevention of esophageal cancer in patients with Barrett's esophagus. Gastroenterology 2012;142:e20-1; author reply e21.

45. Kastelein F, Spaander MC, Steyerberg EW, et al. Proton pump inhibitors reduce the risk of neoplastic progression in patients with Barrett's esophagus. Clin Gastroenterol Hepatol 2013;11:382-8.

46. Rothman KJ, Greenland S. Causation and causal inference in epidemiology. Am J Public Health 2005;95(Suppl 1):S144-50.

47. Alexandre L, Clark AB, Bhutta HY, et al. Statin use is associated with reduced risk of histologic subtypes of esophageal cancer: a nested case-control analysis. Gastroenterology 2014;146:661-8.

48. Moayyedi $\mathrm{P}$, Burch N, Akhtar-Danesh N, et al. Mortality rates in patients with Barrett's oesophagus. Aliment Pharmacol Ther 2008;27:316-20.

49. Bhat S, Coleman HG, Yousef F, et al. Risk of malignant progression in Barrett's esophagus patients: results from a large population-based study. J Natl Cancer Inst 2011:103:1049-57.

50. Hvid-Jensen F, Pedersen L, Drewes AM, et al. Incidence of adenocarcinoma among patients with Barrett's esophagus. N Engl J Med 2011;365:1375-83.

51. Strom BL, Kimmel SE, eds. Textbook of pharmacoepidemiology. Chichester: John Wiley \& Sons, 2006.

52. Hvid-Jensen F, Pedersen L, Funch-Jensen P, et al. Proton pump inhibitor use may not prevent high-grade dysplasia and oesophageal adenocarcinoma in Barrett's oesophagus: a nationwide study of 9883 patients. Aliment Pharmacol Ther 2014;39:984-91.

53. Masclee GM, Valkhoff VE, Coloma PM, et al. Risk of upper gastrointestinal bleeding from different drug combinations. Gastroenterology 2014;147:784-92.e9, quiz e13-4. 